\title{
Bruno Méniel, Renaissance de l'épopée. La poésie épique en France de 1572 à 1623
}

\section{Dario Cecchetti}

\section{Q OpenEdition}

1 Journals

\section{Edizione digitale}

URL: http://journals.openedition.org/studifrancesi/34592

DOI: $10.4000 /$ studifrancesi.34592

ISSN: 2421-5856

\section{Editore}

Rosenberg \& Sellier

\section{Edizione cartacea}

Data di pubblicazione: 1 novembre 2005

Paginazione: 408-409

ISSN: 0039-2944

\section{Notizia bibliografica digitale}

Dario Cecchetti, «Bruno Méniel, Renaissance de l'épopée. La poésie épique en France de 1572 à 1623»,

Studi Francesi [Online], 146 (XLIX | II) | 2005, online dal 30 novembre 2015, consultato il 18 avril 2021.

URL: http://journals.openedition.org/studifrancesi/34592 ; DOI: https://doi.org/10.4000/studifrancesi. 34592

Questo documento è stato generato automaticamente il 18 avril 2021.

\section{(c) 9 (i) $\Theta$}

Studi Francesi è distribuita con Licenza Creative Commons Attribuzione - Non commerciale - Non opere derivate 4.0 Internazionale. 


\title{
Bruno Méniel, Renaissance de l'épopée. La poésie épique en France de 1572 à 1623
}

\author{
Dario Cecchetti
}

\section{NOTIZIA}

BRUNO MÉNIEL, Renaissance de l'épopée. La poésie épique en France de 1572 à 1623, Genève, Droz («Travaux d'Humanisme et Renaissance», CCCLXXXIX), 2004, pp. 555.

1 A poco più di dieci anni dal lavoro fondante di Gabriella Bosco (Tra mito e storia. L'epopea in Francia nel XVII secolo, Alessandria, Edizioni dell'Orso, 1991), che per prima ha costruito un discorso organico sul genere epico in Francia nell'età barocca, Bruno Méniel pubblica una densa thèse sul periodo immediatamente precedente, ma strettamente connesso con quello trattato dalla Bosco (il cui saggio peraltro sembra del tutto ignorato dalla presente ricerca, il che tristemente conferma l'affermarsi fuori Italia dell'assioma «Italicum est, non legitur»). La riflessione, come l'autore stesso sottolinea, verte sulla concezione che l'autunno del Rinascimento e il primo Barocco si fecero dell'epopea, a partire dalla costatazione che «nell'ultimo quarto del XVI secolo e nel primo del XVII secolo, lentamente, si costituisce l'epopea' in quanto genere classico riconosciuto dai trattati di poetica e inquadrato da un arsenale di regole» (p. 11). Il periodo indagato - un cinquantennio - si estende dal 1572, anno in cui vede le stampe La Franciade di Ronsard, al 1623, anno della pubblicazione della préface di Chapelain in cui compare per la prima volta in francese il termine épopée; i testi analizzati sono un'ottantina, alcuni di autori illustri, come Du Bartas, d'Aubigné, d'Urfé, altri di autori poco studiati se non addirittura sconosciuti. Secondo B. Méniel per quest'epoca «è legittimo parlare di una rinascita del poema epico. In questi anni esso si definisce come un lungo racconto in versi lunghi che narra le imprese reali o fittizie degli dei e degli uomini. Costituisce un racconto coerente, perché una stessa Provvidenza opera nella Natura e nella Storia. A questa rinascita possono essere attribuite molteplici cause. 
Perché i francesi del Rinascimento erano impregnati d'una mentalità eroica [...], provavano il bisogno di esprimere nella poesia il loro ideale di valore. Perché erano in preda a una profonda ansia religiosa, trovavano nel genere epico, che esprime l'immistione del divino negli affari umani, il mezzo di placarla mediante una meditazione sulla presenza di Dio nella Storia. Perché l'Antichità aveva situato l'epica in cima alla gerarchia dei generi letterari e la Pléiade ne aveva fatto il limite estremo di ogni impresa poetica, occorreva inevitabilmente confrontarsi con questo genere» ( $p$. 501). Dal momento che nel Cinquecento non si concepisce creazione letteraria che non ponga il problema dell'imitazione, tale problema risulta centrale anche per quanto concerne l'epica, là dove per 'imitazione' si intende sia quella dei classici sia quella dei moderni: per esempio, Du Bartas tiene d'occhio Lucrezio; d'Aubigné, per esprimere il patetico delle guerre civili, fa riferimento a Lucano; altri poeti presi in considerazione da Méniel, come Montreux e Deimier, scelgono come guida Ariosto. Così, la prima parte del lavoro (Théorie et pratique de l'epos', pp. 33-250), che cerca di ricostruire le definizioni teoriche del poema eroico, attraverso anche alcune esemplificazioni ( $\mathrm{Du}$ Bartas, La Gessée, Pontaymery, Schelandre, d'Aubigné) e attraverso la distinzione dei campi confessionali, premette a tale discorso una precisa rassegna dei testi 'recepiti' dalla tradizione classica antica, medievale e rinascimentale italiana. Nella seconda parte (L'éclatement de l'epos', pp. 253-425), dopo avere analizzato le differenti tipologie del poema epico nel Cinquecento francese - poema eroico, poema romanzesco, poema biblico, poema enciclopedico, poema di guerra -, l'autore mette in evidenza come «i poeti della fine del XVI secolo e dell'inizio del XVII, desiderando trattare soggetti diversi possano solo sentirsi allo stretto nel quadro costringente del poema eroico, che secerne un'ideologia tutta sua» e come «i successori di Ronsard abbiano unicamente l'alternativa di sovvertire dall'interno la forma dell'epos o di liberarsene» (p. 425): di qui l'éclatement del genere, per usare il termine caro a Méniel. Nella terza parte (Tentative d'explication de l'éclatement de l'epos', pp. 429-500) di questo éclatement du genre vengono studiati i presupposti filosofici e storici, con interessanti considerazioni su quelli che vengono definiti i partis pris esthétiques dei poeti cattolici e dei poeti protestanti. Per concludere, Bruno Méniel ci offre uno strumento di lavoro utile nella sua chiarezza e nella ricchezza dei dati. 